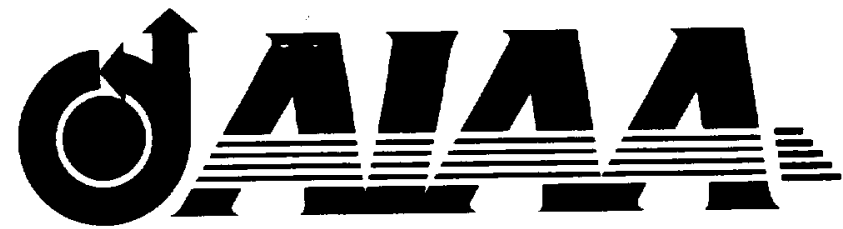 \\ AIAA-2002-2792 \\ Uncertainty Analysis of the Single-Vector Force Balance Calibration System
}

Peter A. Parker, Tianshu Liu

NASA Langley Research Center

Hampton, Virginia

22nd AIAA Aerodynamic Measurement Technology and Ground Testing Conference 24-27 June 2002 / St. Louis, Missouri 


\title{
UNCERTAINTY ANALYIS OF THE SINGLE-VECTOR FORCE BALANCE CALIBRATION SYSTEM
}

\author{
Peler A. Parker*, Tianshu Liu ${ }^{\dagger}$ \\ NASA Langley Research Center \\ Hampton. Virginia 23681
}

\begin{abstract}
This paper presents an uncertainty analysis of the Single-Vector Force Balance Calibration System (SVS). This study is focused on the uncertainty involved in setting the independent variables during the calibration experiment. By knowing the uncertainty in the calibration system, the fundamental limits of the calibration accuracy of a particular balance can be determined. A brief description of the SVS mechanical system is provided. A mathematical model is developed to describe the mechanical system elements. A sensitivity analysis of these parameters is carried out through numerical simulations to assess the sensitivity of the total uncertainty to the elemental error sourees. These sensitivity ecofficients provide valuable information regarding the relative significance of the elemental sources of error. An example calculation of the total uncertainty for a specific balance is provided. Results from this uncertainty analysis are specific to the Single-Vector System, but the approach is broad in nature and therefore applicable to other measurement and calibration systems.

\begin{tabular}{|c|c|}
\hline & Nomenclature \\
\hline$\alpha$ & angle in the pitch direction \\
\hline ( & angle in the roll direction \\
\hline $\bar{x}, \bar{y}, \bar{z}$ & linear distances to center of gravity \\
\hline$\dot{e}$ & position offset \\
\hline$\lambda$ & rotation matrix \\
\hline A & axial force in the BCS \\
\hline$B C S$ & balance coordinate system \\
\hline$C G$ & center of gravity \\
\hline$F$ & force \\
\hline GCS & gravitational coordinate system \\
\hline$g_{x}, g_{v}, g_{z}$ & projection of the gravity vector onto the \\
\hline
\end{tabular}

\footnotetext{
"Rescarch Scientist

${ }^{\ddagger}$ Senior Rescarch Scientist

Copyright 2002 by the American Institute of Aeronautics and Astronautics, Inc. No copyright is asserted in the United States under Title 17, U.S. Code. The U.S. Government has a royally-free license to exercise all rights under the copyright clamed herein for Governmental Purposes. All other rights are reserved by the copyright owner.
}

halance axes

$\begin{array}{ll}N & \text { normal force in the BCS } \\ P & \text { pitching moment in the BCS } \\ R & \text { rolling moment in the BCS } \\ S & \text { side force in the BCS } \\ x, y, z & \text { linear distances } \\ Y & \text { yawing moment in the BCS }\end{array}$

\begin{tabular}{|c|c|}
\hline Subscripts & \\
\hline$a$ & applied weight \\
\hline$b k e$ & below the knife-cdge system \\
\hline f & load point on the fixture \\
\hline$F P S$ & force positioning system \\
\hline IBS & inner bearing support \\
\hline ig & initial geometrical offset \\
\hline$k$ & $\begin{array}{l}\text { load point on the yoke at the location of } \\
\text { the knife-edges }\end{array}$ \\
\hline$K E$ & knife-clge \\
\hline KES & knife-edge attachment system \\
\hline$L T$ & load template \\
\hline$m c l$ & $\begin{array}{l}\text { moment correction due to the yoke load } \\
\text { point position }\end{array}$ \\
\hline$m c^{2}$ & $\begin{array}{l}\text { moment correction due to the yoke CG } \\
\text { location }\end{array}$ \\
\hline$m c^{3}$ & $\begin{array}{l}\text { moment correction duc to the 2-axis } \\
\text { accelerometer CG location }\end{array}$ \\
\hline$p$ & wcight pan \\
\hline $92 x$ & 2-axis accelerometer system \\
\hline$s$ & fasteners to attach FPS to fixture \\
\hline$s u b$ & $\begin{array}{l}\text { sub assembly of the FPS (does not include } \\
\text { fasteners) }\end{array}$ \\
\hline$w$ & precision weights \\
\hline$y k$ & yoke \\
\hline
\end{tabular}

Direct measurement of aerodynamic loading is fundamental to wind tunnel testing. An instrument known as a force balance provides these measurements in six degrees of freedom. The balance is mounted internally in a scaled wind tunnel model and measures three orthogonal components of acrolynamic force (normal, axial, and side force) and three orthogonal 
the non-metric positioning system, and the oricntation of the balance is precisely measured on the inctric end using the accelerometer system. This accelerometer system provides the components of the gravitational vector projected onto the three-axes of the balance coordinate system. Combining the measured gravitational components on the balance axes and the known applied weight enables the determination of the three force components.

The three balance moment components are a function of the force vectors and the position of the point of load application in three-dimensional space relative to the balance moment enter (BMC). The $B M C$ is a defined location in the balance coordinate system that serves as a reference point in which the moment components are described. The point of load application is sel using the multiple degree-of-freedom force positioning system. This system utilizes a novel system of hearings and knife-cdge rocker guides 10 maintain the load orientation, regardless of the angular orientation of the balance, which makes the point of load application independent of the angular oricntation of the balance. Stated another way, when the balance is manipulated in three-dimensional space, the point of load application remains fixed.

A mechanical system provides the ability to set the independent variables during the calibration experiment as described above. While the SVS hardware system is fundamentally simpler than other force calibration systems, the nature of the six-component calibration experiment still requires multiple mechanical degrees of freedom. A drawing of the primary force application components of the SVS is provided in Figure 2. The system consists of a number of high-precision mechanical components that contribute to the total uncertainty of the forces and moments set during the calibration experiment. The ability to measure or calculate the geometric properties and weights of these components provides the elemental sources of error. The mathematical relationship hetween the component properties and the independent variables (forces and moments relative to the balance coordinate system) will now be presented.

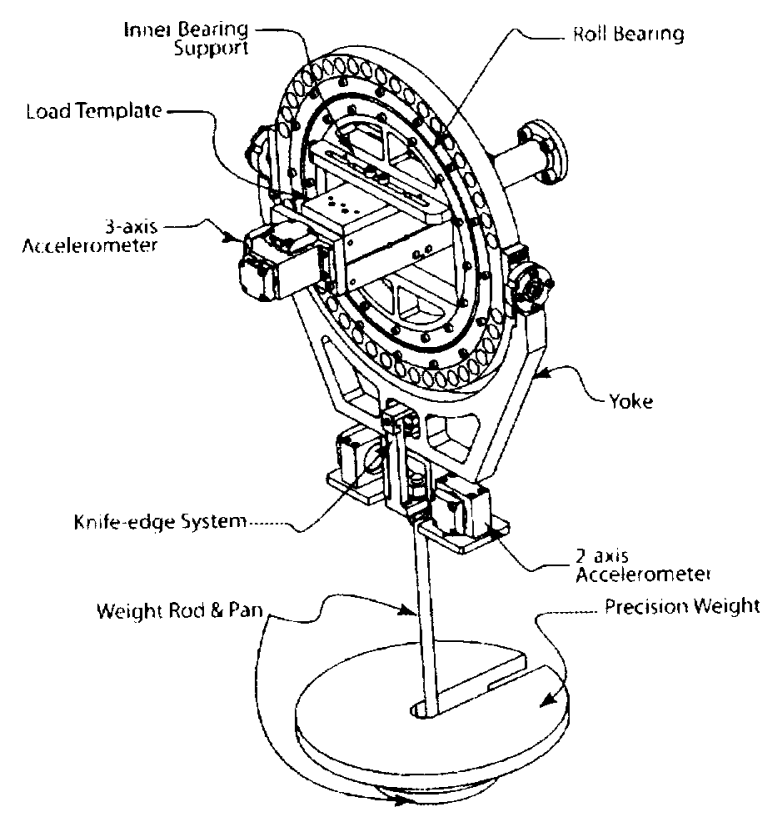

Figure 2. Single-Vector Diagram

Forces Due to the Applied Weights

The computation of the independent variables is divided into two parts. First. the forces are computed followed by the moments. The total applied force is a combination of the precision weights and the measured weight of the rod and pan system.

$$
F_{s}=F_{n}+F_{n} \text {. }
$$

The forces in the balance coordinate system (BCS) are

$$
\left[\begin{array}{l}
N_{a} \\
A_{a} \\
S_{a}
\end{array}\right]=F_{a}\left[\begin{array}{l}
g_{a} \\
g_{a} \\
g_{1}
\end{array}\right] .
$$

The applied force is multiplied by the projection of the gravitational vector onto the balance axes. In other words, the total force is decomposed into the vector components of the BCS.

\section{Forces Due to the Force Positioning System (FPS)}

The applicd force duc to the force positioning system (FPS) is a combination of the FPS subsystem weight and the fasteners that attach the FPS to the load template as follows.

$$
F_{r p s}=F_{\text {sut }}+F_{\mathrm{s}} .
$$

The forces relative to the BCS are

$$
\left[\begin{array}{c}
N_{F P S} \\
A_{F P S} \\
S_{t P S}
\end{array}\right]=F_{F P S}\left[\begin{array}{l}
g_{2} \\
g_{V} \\
g_{V}
\end{array}\right] .
$$

Moments Due to the Applied Weights

The moments generated due to the applied weight are a function of the magnitude and position of the 
The first moment correction is

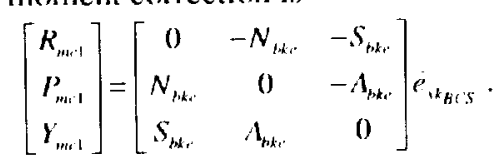

Moments Correction Due to the Eccentricity of the Center of Gravity of the Yoke

A sccond moment correction is based on the elfect of the center of gravity (CG) of the yoke being rotated relative to the BCS. In a similar manner, the position of the $\mathrm{CG}$ is determined by calculating its location relative to a GCS and then rotating it into the BCS,

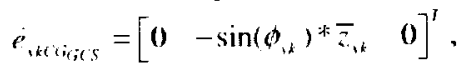

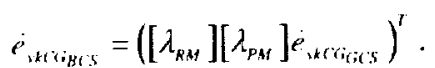

The force applied at this rotated location is due to the weight of the yoke. The forces relative to the BCS is

$$
\left[\begin{array}{l}
N_{i k c i} \\
A_{v k c i} \\
S_{v k c i}
\end{array}\right]=F_{v k}\left[\begin{array}{l}
g_{2} \\
g_{2} \\
g_{1}
\end{array}\right] \text {. }
$$

The second moment correction is equal to

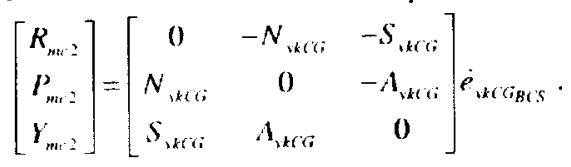

Moment corrections due to the Eccentricity of the Center of Gravity of the Two-Axis Accelerometer System

The third moment correction is based on the location of the center of gravity of the two-axis accelerometer system relative to the BCS. A similar procedure is followed to compute the location relative to the GCS.

$$
\dot{e}_{42, \alpha c_{i i t i S}}=\left[\begin{array}{lll}
0 & -\sin \left(\phi_{v k}\right) * \bar{z}_{422} & 0
\end{array}\right]^{r},
$$

rotate into the $\mathrm{BCS}$.

$$
\dot{e}_{42 \times C B_{B S C} S}=\left(\left[\lambda_{R M}\right]\left[\lambda_{P M}\right] \dot{e}_{4 x_{A G S S}}\right)^{T} \text {. }
$$

compute the forces,

$$
\left[\begin{array}{l}
N_{4=2} \\
A_{42+} \\
S_{42=}
\end{array}\right]=F_{42=}\left[\begin{array}{l}
g_{2} \\
g_{1} \\
g_{1}
\end{array}\right]
$$

and calculate the moment correction.

$$
\left[\begin{array}{l}
R_{m+3} \\
P_{m+3} \\
Y_{m+3}
\end{array}\right]=\left[\begin{array}{ccc}
0 & -N_{42,} & -S_{422} \\
N_{422} & 0 & -A_{422} \\
S_{42,} & A_{422} & 0
\end{array}\right] \dot{P}_{42 B B S} .
$$

Total Forces and Moments about the BCS

Combining the intermediate results of the forees acting relative to the BCS provides the total forces as

$$
\left[\begin{array}{l}
N \\
A \\
S
\end{array}\right]=\left[\begin{array}{l}
N_{d} \\
A_{d} \\
S_{n}
\end{array}\right]+\left[\begin{array}{l}
N_{F P S} \\
A_{K P S} \\
S_{K P S}
\end{array}\right]
$$

To calculate the total moments relative to the BCS, the moments assuming no eccentricity on the load point are combined with the three moment corrections as

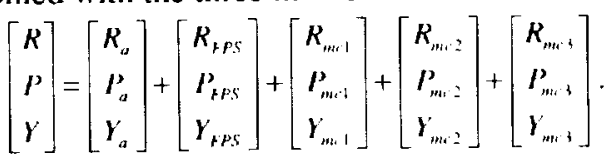

Note that the eccentricity of the load point does not require corrections to the lotal forces.

\section{Uncertainty Analysis}

Based on the mathematical models presented, the total uncertainty of each mcasured component $\left(X_{k}\right)=(N, A, P, R, Y, S)$ is given by the error propagation equation ${ }^{|3,4|}$

$$
\frac{\operatorname{var}\left(X_{k}\right)}{X_{k, S_{k}}^{2}}=\sum_{i, j}^{M} S_{i k} s_{j k} \rho_{i j} \frac{\left[\operatorname{var}\left(\zeta_{1}\right) \operatorname{var}\left(\zeta_{j}\right)\right]^{1 / 2}}{\zeta \zeta_{j}}
$$

where

$$
\rho_{i j}=\operatorname{cov}\left(\zeta_{i} \zeta_{j}\right) /\left(\operatorname{var}\left(\zeta_{i}\right) \operatorname{var}\left(\zeta_{j}\right)\right]^{1 / 2}
$$

is the correlation coefficient between the variables $\zeta$, and $\zeta_{j}, \operatorname{var}\left(\zeta_{i}\right)=\left\langle A \zeta_{i}^{2}\right\rangle$ and $\left(\alpha \cdot\left(\zeta_{i} \zeta_{j}\right)=\left\langle A \zeta_{i} \Lambda_{j}\right\rangle\right.$ are the variance and covariance, respectively, and the notation $<>$ denotes the statistical assemble average. Here the variables $\left\langle\zeta_{i}, i=l \cdots M\right|$ denote a set of the parameters in the mathematical models for all the system elements of the SVS. The normalized sensitivity coefficients $s$ are defined as

$$
S_{i k}=\left(\zeta_{i} / X_{t s k}\right)\left(\partial X_{k} / \partial \zeta_{i}\right)
$$

where $X_{r s k}$ is the full-scale range of $X_{k}$.

A typical balance was chosen as an example to compute the total uncertainty. The SVS experiment design involves 54 unique combinations of the six independent variables (the forces and moments). Within the 54 runs there are combinations of six variables simultancously, two variables, and single variable set points, also referred to as pure-loads. The uncertainty is dependent on the particular combination of variables applicd. Stated another way, the uncertainty depends on the simulaneous levels of the variables for a particular required combination in the calibration experiment design. A detailed analysis was performed for cach combination. 
Table I. Parameiers and Elemental Error Sources of the SVS

\begin{tabular}{|c|c|c|c|c|c|c|c|}
\hline & & & Range & Range & Mean & Standard & \\
\hline Index & Variable & Description & Low & High & Level & Deviation & \\
\hline 1 & $g_{7}$ & projection of gravity vector on $z$-axis & -1 & 1 & & 0.000020 & g \\
\hline 2 & $g_{\lambda}$ & projection of gravity vector on $x$-axis & -1 & 1 & & $0.00(x) 20$ & $\mathrm{~g}$ \\
\hline 3 & $g_{1}$ & projection of gravity vector on $y$-axis & -1 & 1 & & $0.000(0) 20$ & $g$ \\
\hline 4 & $x_{l, T}$ & CMM mcasured $x$ location on load template & $-1.56,25$ & 1.5025 & & 0.000200 & inches \\
\hline 5 & $y_{l t}$ & CMM measured y location on load tcmplate & -0.625 & 0.625 & & 0.000200 & inches \\
\hline 6 & 2.1 .1 & CMM mcasured z location on load template & constant & & 0.0000 & 0.000200 & inches \\
\hline 7 & $F_{w}$ & measured forec duc to precision weights & 0 & 160 & & $0.01 \%$ & $\%$ of lis \\
\hline 8 & $F_{r}$ & measurcd force duc to rod and pan assembly & constant & & 3.1560 & 0.000473 & Ihs. \\
\hline 9 & $r_{s}$ & measured force due to attachment screws & constant & & 0.0322 & $0.00(x) 005$ & Ihs. \\
\hline 10 & $\bar{z}_{\mathrm{s}}$ & calculated $\%$-distance to the centroid of serews & & & $-1.75(\mathbf{X})$ & 0.001000 & inches \\
\hline 11 & $F_{\text {IBS }}$ & measured force duc to the inner bearing support & constanı & & 6.7871 & 0.001018 & libs. \\
\hline 12 & $\bar{s}_{I B S S}$ & calculated $z$-distance to CG of IBS & constant & & -0.2867 & 0.001000 & inches \\
\hline 13 & $F_{\text {PPS }}$ & measured force due to FPS & constant & & 30.1575 & $0.0(14524$ & libs. \\
\hline 14 & $x_{F P S}$ & CMM measured $x$ location of pins in FPS & constiant & & 0.0025 & 0.000200 & inches \\
\hline 1.5 & $y_{F P S}$ & CMM measured y location of pins in FPS & constant & & -0.0006 & 0.000200 & inches \\
\hline 16 & Zrps & CMM mcasured $\%$ location of pins in FPS & constant & & 0.0005 & 0.000200 & inches \\
\hline 17 & $r_{v k}$ & measured force due to the yoke & constant & & 8.06 .39 & 0.001210 & Ibs. \\
\hline 18 & $\bar{\varepsilon}_{x x}$ & calculated $z$-distance $\mathrm{to}$ CG of yoke & constant & & 4.7439 & 0.000500 & inches \\
\hline 19 & $x_{v k}$ & CMM measured $x$ location of hole in the yoke & & & $0 .(x)(x)$ & 0.000200 & inches \\
\hline 20 & $y_{v k}$ & CMM measured y location of hole in the yoke & & & 0.00122 & 0.000200 & inches \\
\hline 21 & $F_{q 2 x}$ & measured force due to the 2-axis accel. sys. & constant & & 1.4054 & 0.000211 & libs. \\
\hline 22 & $y_{q 2 . x}$ & measured y-distance to the CG of 2-axis accel. & constant & & 0.0375 & 0.002000 & inches \\
\hline 23 & $\therefore \cdot q 2 x$ & measured $z$-distance to the CG of 2-axis aceel. & constant & & 10.5215 & 0.000200 & inches \\
\hline 24 & $\alpha_{. k}$ & measured angle of the yoke orientation in pitch & -1 & 1 & & 0.001000 & degrees \\
\hline 25 & $\varphi_{i k}$ & measured angle of the yoke oricntation in roll & -1 & 1 & & 0.001000 & degrees \\
\hline 26 & $F_{K E S}$ & measured force duc to the knife-edge system & constant & & 1.2275 & 0.000184 & Ibs. \\
\hline 27 & $Z_{K K}$ & CMM measured $\%$ loaction of knife-edge systcm & constant & & 8.0844 & 0.000200 & inches \\
\hline
\end{tabular}



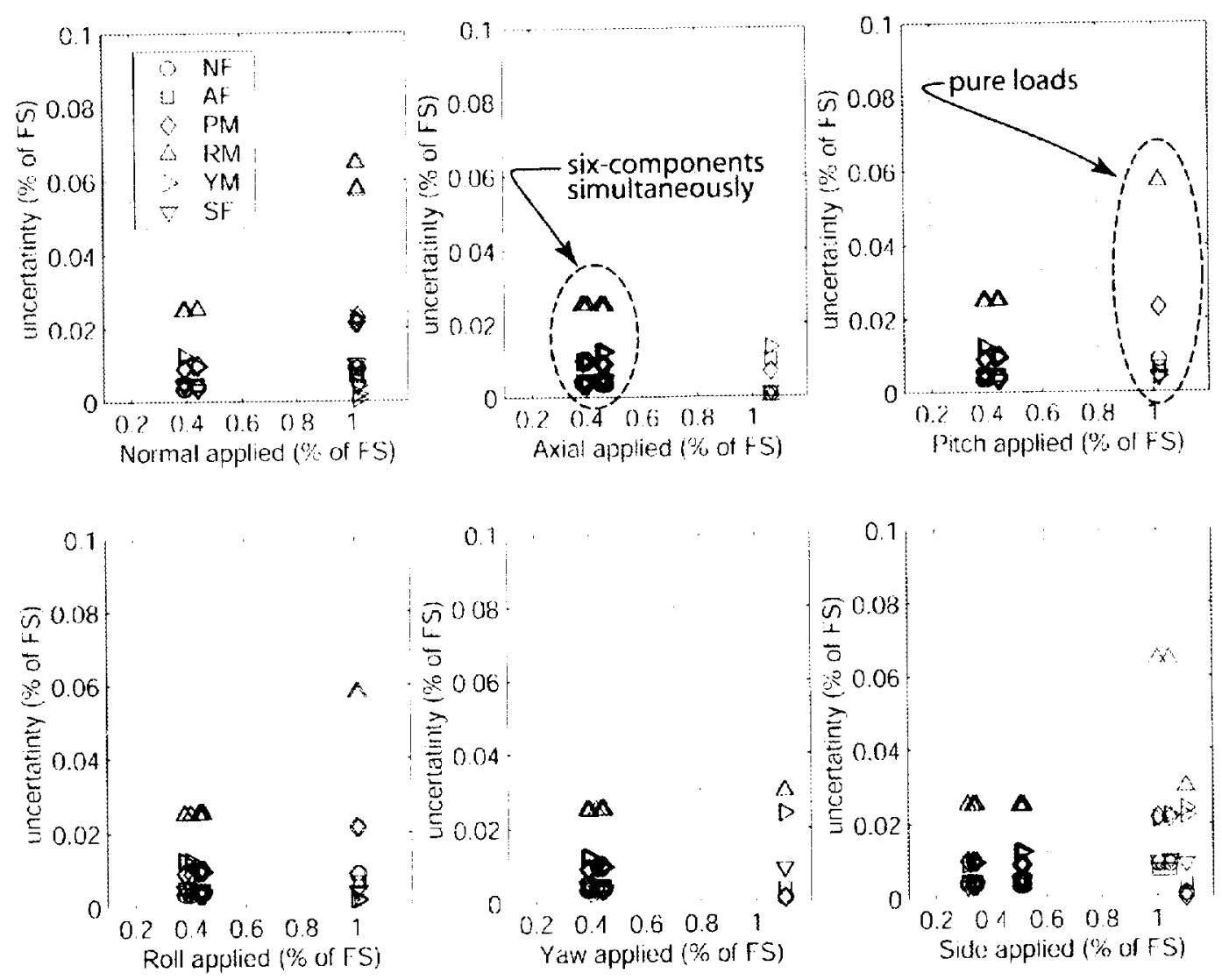

Figure 4. Total Uncertainty of Experimental Design Points

\section{Concluding Remarks}

An uncertainty analysis of the Single-Vector System has been presented. This analysis has provided insight into the uncertainty in selting the independent variables during a calibration experiment. The computation of the total uncertainty is necessary to define the atlainable accuracy of a specific balance under calibration.

A complete mathematical model that defines the relationship between the elemental sources of error and the desired forces and moment has been presented. The sensitivity of the forces and moments to each elemental source of error has illustrated the dominant sources. An example of the calculation of the total uncertainty has been provided for a specific balance

A rigorous uncertainty analysis of the force calibration system is necessary to be able to quantify the limits for a specific balance calibration. This paper documents the uncertainty analysis of the SVS and presents a general method that is applicable to other force balance calibration systems.

\section{References}

1) Parker, P.A.; Morton, M.; Draper, N.: Line. W .: A Single-Vector Force Calibration Method Featuring the Modern Design of Experiments (Invited). AIAA 20(01-(0170, 38th Acrospace Sciences Mecting and Exhibit. Reno, Nevada. January $2(X) 1$.

2) Parker. P.A.; DeLoach, R.: Response Surface Methods for Force Balance Calibration Modeling. IEEE 19th International Congress on Instrumentation in Acrospace Simulation Facilitics, Cleveland. Ohio, August 2001.

3) Colcman, H.W.; Stcele, W.G.: Experimentation and Uncertainty Analysis for Engineers, $2^{\text {nd }}$ Edition. John Wilcy and Sons, 1999.

4) Ronen, Y.: Uncertainty Analysis. CRC Press, Boca Raton. FL. 1988. 
